Volume 5, Issue S1 (2020), pp. 15-20

Journal of School Administration Research and Development

ISSN: 2470-8496 Print/ ISSN: 2470-850X Online

ojed.org/jsard

\title{
Examining the Usefulness of Mindfulness Practices in Managing School Leader Stress During COVID-19 Pandemic
}

\author{
Lu Liu \\ University of La Verne, USA
}

\begin{abstract}
As part of a larger evaluation study on the impact of mindfulness practices on school leaders' capacity to promote healing-centered engagement with students and teachers who have a history of trauma, toxic stress, and/or underperformance, mindfulness practices turned out to be critically important during COVID-19 when school leaders face unprecedented difficulties and challenges in transitioning the instructions online. The two mindfulness strategies found to have the highest scores are breathing practices and the concept of "being the thermostat, and not the thermometer." The study shows that learning and practicing mindfulness is a long process that takes time and space. Future studies are recommended to focus on the sustainability and group difference issues.
\end{abstract}

Keywords: COVID-19 pandemic, mindfulness practices, school leaders, stress management

Responding to the spread of a respiratory illness caused by a novel coronavirus (COVID-19), many school districts across the nation, including the school district under study, transitioned to distance learning at the end of the 2019-2020 school year, starting in mid-March, and for the first half of the $2020-2021$ school 
year. Facing unprecedented difficulties and challenges, school/district administrators continued to be tasked with ensuring that all students and families had the necessary resources to support distance learning. However, recent research revealed several challenges caused by such rapid transition: (a) insufficient online learning infrastructure (e.g., Zoom crashes and security issues); (b) teachers' lack of experiences in online technology use and online learning pedagogy; (c) inadequate time for planning and decision-making for the administrators; (d) the disparities in the students' home environment to accommodate online learning; and (e) distress and concerns among students, parents, teachers, and the school/district administrators (Bergdahl \& Nouri, 2020; Wang et al., 2020). As part of a larger evaluation study on the impact of mindfulness practices on school leaders' capacity to promote healing-centered engagement with students and teachers who have a history of trauma, toxic stress, the evaluation results provided us a rare opportunity to assess the impact of mindfulness practices during a difficult and unforeseen situation.

The Mindful Leaders Project included residential mindfulness immersion conferences (2.5 days/2 nights), bi-weekly principal coaching in mindful leadership, school site principal visits, and bi-monthly professional learning opportunities during regularly scheduled principals' meetings. Over the course of an entire school year from September 2019 to June 2020, district leadership was immersed in a process that aimed to help them establish a personal mindfulness practice for professional self-care, engage in conscious transformation, and establish a school culture rooted in mindful leadership in a school district in Southern California.

The major research questions are: (a) How did the administrators apply what they learned in the Mindful Leader Project to manage their stress and maintain a sense of well-being and calm?, (b) It was useful to examine which strategies the administrators deemed to be most helpful?, and (c) What barriers or concerns did they have about mindful practices? The research design is mixed method in nature in which both quantitative and qualitative data were collected and analyzed. For the COVID-19 survey, it was sent out to school/district leaders who attended one of the two conferences, and 45 responses were collected.

\section{MINDFULNESS PRACTICES AND STRESS REDUCTION}

Mindfulness is rooted in Buddhism and is defined as "paying attention in a particular way: on purpose, in the present moment, and non-judgmentally" (Kabat-Zinn, 1994, p.4). Trait mindfulness is positively related to emotional 
intelligence (Miao et al., 2018), self-compassion and tolerance for ambiguity (Fulton, 2016), coping skills and motional regulation (Clark, 2020), and management self-efficacy (Becker \& Whitaker, 2018). All of them are important characteristics of a successful school leader. At the organizational level, mindfulness enables embodied wisdom in leaders (Rooney et al., 2019), improves employee well-being and job performance (Reb et al., 2014), and proves to be critical for building school trust (Hoy et al., 2006).

Fortunately, the level of mindfulness can be improved through mindfulness practices. The impact of mindfulness-based stress reduction (MBSR) practices has been studied on school leaders, teachers, students, and in a variety of clinical and business settings. These studies generally found that the mindfulness practices were effective in managing work-related stress (Żołnierczyk-Zreda et al., 2016), reducing social anxiety and aggressive behaviors (Clark, 2020), and reducing burnout and mental distress (Vonderlin et al., 2020).

However, it remains unknown how much of the mindfulness practices can be transferred in daily operational practices when facing unprecedented difficulty and challenges in events such as COVID-19, especially considering that the school leaders in this study had less than one year's mindfulness training even though mindfulness was used as a strategy to improve organizational resilience in the face of global recession (Żołnierczyk-Zreda et al., 2016). Moreover, since many studies are short-term or cross-sectional in nature, the sustainability of the mindfulness practices and the group differences (e.g., gender, ethnicity, age, and experiences) remain a largely unexplored area ( $\mathrm{Li}$ et al., 2006; Rufa, 2018).

\section{CONCLUSIONS/ IMPLICATIONS}

Based on the participants' feedback, mindfulness practices turned out to be critically important during COVID-19, as one principal said, "it is darn near impossible with so many unknowns, but I believe our work with mindfulness is what has enabled me to maintain calmness and be the thermostat." Some participants even treated this time as a gift for allowing them more practice time. For example, one participant said, "Actually COVID-19 has been the best thing for me as it has provided me time to work on my mindfulness practice. I have the opportunity now to start and end with yoga. This allows for me to reset my vagus nerve before hopping into my daily schedule." 
Based on the results, the two mindfulness strategies with the highest scores are the breathing practices and the concept of "being the thermostat, and not the thermometer" in guiding leadership disposition during COVID-19. Other strategies such as "healing-centered engagement," "Vagus Nerve Reset practice," and "honoring life transitions with mindfulness" have scores close to "helpful" as well. Many participants applied what they learned in the mindfulness training to their daily life and work so that they could function well when facing significant increases in workload and/or stress. Therefore, the idea of self-care and maintaining calmness sustained the school leaders during this difficult time. The results match with past research in the effect of mindfulness strategies such as breathing exercises in reducing anxiety and depression (Lalande et al., 2012) and the importance of leaders' self-care practices before serving others in need (Pipe \& Bortz, 2009).

One of the major lessons learned in this study is that practicing mindfulness is a long process which takes time and space. It must be intentional, with participants accepting and valuing mindfulness practices as a personal commitment. Additionally, the participants needed to set up a routine to make it habitual and allow time to practice mindfulness or not to have excuses. For example, Harris et al. (2016) identified the positive effect of a school-based mindfulness intervention that incorporated daily practices. However, when a routine is not established, studies have showed that the participants may not continue the mindfulness practices after the completion of a study (Rufa, 2018). In the COVID-19 survey, some participants thought the on-going support and encouragement from their coaches was the reason for their continued practice of mindfulness in this challenging time. Other successful strategies include taking 5 to 10 minutes each day to focus on breathing and mindfulness techniques, creating a quiet space in one's office, and finding a favorite place to reset after dealing with difficult parents and/or students. Participants may try one or multiple strategies until they establish a successful routine (Hoy et al., 2006).

Based on the assessment data in this study, females in general had lower mindfulness scores than males. Although past research has demonstrated the positive effect of mindfulness practices on improving daily psychological wellbeing, such effect may work on males and females differently (Rojiani et al., 2017). This finding may be related to the fact that men and women cope with psychological distress differently, as the former externalize their distress and the latter internalize their distress (Li et al., 2006). However, how different coping strategies affect the mindfulness practices remains to be seen. 
Therefore, it's recommended that (a) although placing mindfulness practices on one's daily agenda is an individual behavior, some support from the district level would be helpful. Policies and practices such as dedicating time during school to practice mindfulness will help promote the mindfulness practices; (b) school leaders pay attention to group differences in practicing mindfulness. Potentially differentiated inventions can be provided based on the group differences in order to maximize the effect of the mindfulness training; (c) individuals identify strategies to sustain mindfulness practices in order to make it intentional and habitual.

\section{REFERENCES}

Becker, B. D., \& Whitaker, R. C. (2018). The association between dispositional mindfulness and management self-efficacy among early childhood education managers in Head Start. Mindfulness, 9(2), 636-644.

Bergdahl, N., \& Nouri, J. (2020). Covid-19 and Crisis-Promoted Distance Education in Sweden. Tech Know Learn, Sep 2: 1-17.

Clark, L. B. (2020). Utilizing mindfulness based CBT to address anger and aggression in middle schools. Journal of Child and Adolescent Counseling, 6(2), 97-109.

Fulton, C. L. (2016). Mindfulness, self-compassion, and counselor characteristics and session variables. Journal of Mental Health Counseling, 38(4), 360374.

Harris, A. R., Jennings, P. A., Katz, D. A., Abenavoli, R. M., \& Greenberg, M. T. (2016). Promoting stress management and wellbeing in educators:

Feasibility and efficacy of a school-based yoga and mindfulness intervention. Mindfulness, 7(1), 143-154.

Hoy, W. K., Gage, C. Q., III, \& Tarter, C. J. (2006). School mindfulness and faculty trust: Necessary conditions for each other? Educational Administration Quarterly, 42(2), 236-255.

Kabat-Zinn, J. (1994). Wherever You Go. There You Are: Mindfulness Meditation in Everyday Life. Piatkus.

Lalande, L., Bambling, M., King, R., \& Lowe, R. (2012). Breathwork: An additional treatment option for depression and anxiety? Journal of Contemporary Psychotherapy: On the Cutting Edge of Modern Developments in Psychotherapy, 42(2), 113-119.

Li, C. E., DiGiuseppe, R., \& Froh, J. (2006). The roles of sex, gender, and coping in adolescent depression. Adolescence, 41, 409-415. 
Miao, C., Humphrey, R. H., \& Qian, S. (2018). The relationship between emotional intelligence and trait mindfulness: A meta-analytic review. Personality and Individual Differences, 135, 101-107.

Pipe, T. B., \& Bortz, J. J. (2009). Mindful leadership as healing practice: Nurturing self to serve others. International Journal for Human Caring, 13(2), 34-38.

Reb, J., Narayanan, J. \& Chaturvedi, S. (2014). Leading Mindfully: Two Studies on the Influence of Supervisor Trait Mindfulness on Employee WellBeing and Performance. Mindfulness, 5, 36-45.

Rojiani, R., Santoyo, J. F., Rahrig, H., Roth, H. D., \& Britton, W. B. (2017).

Women benefit more than men in response to college-based meditation training. Frontiers in Psychology, 8:551.

Rooney, D., Küpers, W., Pauleen, D., \& Zhuravleva, E. (2019, November 13). A developmental model for educating wise leaders: The role of mindfulness and habitus in creating time for embodying wisdom. Journal of Business Ethics. https://link.springer.com/article/10.1007/s10551-019$\underline{04335-0}$

Rufa, P. (2018). An action research study on the impact of mindfulness based stress reduction on school leadership (Publication No. 10930506) [Doctoral dissertation, Hofstra University]. ProQuest Dissertations Publishing.

Vonderlin, R., Biermann, M., Bohus, M. et al. (2020). Mindfulness-Based Programs in the Workplace: A Meta-Analysis of Randomized Controlled Trials. Mindfulness, 11, 1579-1598.

Wang, G., Zhang, Y., Zhao, J., Zhang, J., \& Jiang, F. (2020). Mitigate the effects of home confinement on children during the COVID-19 outbreak. Lancet (London, England), 395(10228), 945-947.

Żołnierczyk-Zreda, D., Sanderson, M., \& Bedyńska, S. (2016). Mindfulnessbased stress reduction for managers: A randomized controlled study. Occupational Medicine, 66(8), 630-635.

Lu Liu, $\mathrm{PhD}$, is an Associate Professor in the Organizational Leadership Doctoral Program, University of La Verne. Her major research interests are in the area of research methodology, program evaluation, and education leadership. Email: 1liu2@laverne.edu 